A subject of immediate practical application, namely, grass conservation, will be discussed on Monday morning. This will be opened by Mr. Martin Jones, who will deal with "The Place of Grassland in Modern Food Production". He will be followed by Dr. Watson, Mr. Roberts and Prof. Kerr, who will speak respectively on the scientific, economic and enginecring aspects of grass conservation.

A subject suited to the locality is that of seed potato growing. A discussion on this will be opened by Mr. Wedderspoon, who will speak as a grower. Virus diseases and seed potatoes will bo considered by Dr. Cockerham, and Dr. McIntosh will deal with the importance of variety in potato production.

An innovation this year is the display of a series of agricultural films by Mr. Miore and Dr. Gordon of the Department of Agriculture of the University of Edinburgh. These will be shown on the Monday afternoon.

\title{
THE INSTITUTE OF MEDICAL AND VETERINARY SCIENCE, ADELAIDE
}

\section{OPENING OF NEW LaBORATORIES}

\author{
By Sir Charles Martin, C.M.G., F.R.S.
}

\begin{abstract}
THE new Institute of Medical and Veterinary Science was officially opened on May 24 by Sir George Murray, Lieutenant-Governor of South Australia and Chancellor of the University of Adelaide. It represents in part an extension and modification of the pre-existing facilities for the study of pathology, bacteriology and biochemistry at the Adelaide Hospital, which is the School of Medicine of the University; in part, it is a new development :
\end{abstract}

(1) To carry out, with more adequate accommodation, equipment and staff than heretofore, the routine investigations in the subjects mentioned above for the Adelaide Hospital, Stock and Brands Department, country hospitals and private practitioners.

(2) To engage in research into the causation, diagnosis and cure of disease in man and animals.

(3) By bringing into a building devoted to these purposes the University teaching departments of pathology, bacteriology and applied physiology, as well as a properly equipped clinical lecture theatre previously wanting in Adelaide, to attempt to inculcate in the medical students that appreciation of the significance of laboratory medicine to which at present comparatively little attention is paid, and thus to render their later outlook more truly scientific.

The Institute will work in the closest collaboration with the Adelaide Hospital on one hand and with the University on the other, and adds greatly to the amenities of the Adelaide Medical School.

The Institute is the result of a joint effort on the part of the University and members of the staff of the Hospital to bring together in closer association the Department of Pathology of the University and the pathological services of the Hospital. As the two institutions adjoin there were no topographical reasons why this should not bo brought about. The Institute is located in the grounds of the Hospital. It faces Frome Avenue, on the opposite side of which is the University campus. It extends backwards amidst the hospital buildings, which are arranged on the pavilion system. It is, therefore, suitably placed for service to the Hospital and readily accessible to patients. It is also close to the other scientific institutes of the University and to the University library. The style is Georgian, with a pleasing simple frontage, and it has been judiciously planned so as to permit of future extension.
In 1936 the authorities wero fortunate in securing Dr. E. Weston Hurst for its first director. Shortly afterwards, the University appointed Dr. Hurst to a research professorship which whilst it gives him the status of a senior officer in the University makes no demands upon the director for teaching duties.

Building was not commenced until 1937, so that the details of planning and equipment were able to bo made under his supervision, and it is clear from the description of the arrangement of the Institute that they have been admirably conceived and carried out. Facilities for research have had due consideration.

The Institute has two stories with a half-basement. It contains some twenty laboratories, a library, two classrooms, a lecture theatre, a complete operating suito for animals, common rooms for staff and students, offices for the director, and an abundant supply of general service rooms (hot room, cold room, photographic suite, etc.), plenty of store rooms and a workshop.

On the first floor is a museum, $80 \mathrm{ft}$. $\times 40 \mathrm{ft}$., to house the collection of specimens of morbid anatomy hitherto inadequately accommodated at the Uni. versity. Perhaps the most notable feature of the Institute is its fine animal house. This is situated 100 yards from the main building. Especial care has evidently been devoted to its construction and equipment for tho breeding of experimental animals and the convenience and accuracy of experimental work. Expense has not been spared for this essential part of an institute for research in pathology, and it cost one tenth as much as the main building.

Tho total cost has been $£ 53,000$. $£ 15,000$ was contributed by three notable benefactions, $£ 10,000$ by the commissioners of charitable funds and the rest by the Government of South Australia.

The Institute is governed by a council of six representing the Adelaide Hospital, the University and the veterinary interests of the State.

The Adelaide Hospital being a Government institu. tion, the surrender of a measure of its sovereignty and some of its territory required a special Act of Parliament. By this Act, the Government undertakes to contribute $£ 10,000$ a year towards the maintenance of the Institute, the remainder being derived from the University Chest and by the allocation of certain 
trust funds at the disposal of the University. As is usual, the provision of a sufficient revenue is left to luck. If the amount of research is to be enough to justify the accommodation, much moro than is at present forthcoming will be required to provide modest salaries for the upkeep of research workers. 'There is no lack of suitable graduates in Australia who are anxious to devote themselves to investigation if they can see a reasonable prospect of a living wage. At present they come to Great Britain with Rhodes and Beit and other research studentships and when trained remain, as there are not openings for them in their mother country. This drainage is not too good for Australia.

Both University and Hospital are to be congratulated on having secured convenient modern accommodation and equipment for teaching and research in pathology and for the better treatment of patients and investigation of their diseases. They are still more to be congratulated on having surmounted the difficulties always attending combined action by the two corporate bodies under separate governance.

Close association of pathology with clinical medicine is desirable. A pathological institute can function apart from a hospital, but its scope is restricted, and researches tend to become remote from the immediate problems of human medicine and the workers lack the stimulus to effort which is afforded by contact with the sick.

An unusual feature in the new Institute at Adelaide is the inclusion of the study of animal pathology as one of its main objects. For some years investigations of diseases of farm animals have been carried on at the pathological laboratory at the Adelaide Hospital, the Government providing a veterinary officer and technical staff for the purpose. The continuation of this association of the study of human and animal diseases will be both convenient and advantageous, for pathology has no specific boundaries, and have not most of the recent discoveries in human pathology been, perforce, achieved by experimenting with animals?

\section{SYNTHETIC SOUND}

$\mathrm{I}_{\mathrm{b}}^{\mathrm{N}}$ Philips Technical Review of June, which is edited by the Research Laboratory of Philips Glow Lamp Factory, Eindhoven, Holland, there is an interesting paper on "Synthetic Sound" by J. F. Schouten. A sound of prescribed character of periodic vibra. tions, in other words, a sound consisting of harmonic components of prescribed amplitude and phase, is obtained synthetically. This method permits a closer study of a number of problems which are connected with the nature of the perception of sound. The principle used is to make a beam of light vary as a function of the time in the desired wave form. The beam is incident on a photo-electric cell and actuates a loud-speaker. A paper stencil is made and is uniformly illuminated by a point source of light from a tungsten are lamp placed at a considerable distance away. Behind the stencil there is a rotating aluminium disk in which nine slits have been made, each with a width of $1 \mathrm{~mm}$. and at distances of $40^{\circ}$ from each other. Behind the disk, which is driven by a motor, is a lens which focuses the light source upon the photo-electric cell. The only light which can fall upon the photo-electric cell is that which has passed through the part of the stencil cut away and one of the slits. When the disk is turning, the amount of light transmitted at each moment is proportional to the height of the part cut away at the point behind which there is a slit at that moment.

The centre of the wave form is situated on the extension of the axle of the motor. With the arrange. ment used negative values of the light transmissibility cannot be produced, and so a constant quantity equal to the largest negative value occurring is added to all the ordinates of the wave form to be reproduced. The frequency was determined by regulating the number of revolutions per minute of the motor. If the desired form is given as the sum of a number of sine-shaped components, the components can be added and the resultant wave form cut out. It is easy to cut out the forms separately one above the other.
An attractive property of this apparatus is that it makes it possible to study directly the influence exerted on sound perception by changes in the wave form. For examplo, when several components havo been cut out one above the other, any one of these components can be made to disappear, simply by screening this part of the stencil from the light.

According to a law of acoustics which was formu. lated by Ohm, a definite pure tone will bo observed in a synthetic sound, when a component of the frequency in question occurs in the Fourier analysis of the wave form. According to a rule enunciated by Helmholtz, the sound perception will further depend entirely on the relative intensity with which the different components occur and will be independent of the relative phase of these components.

The author accounts for these facts in a simplo way, which seems to be permissible anatomically, that there are in the ear a large number of resonators tuned for different frequencies. This mechanism explains in the first place the fact that the ear carries out, as it were, a.Fourier analysis of the sound while it furthermore makes it possible to suppose that the stimuli which are sent from each resonator to the brain depend exclusively upon the intensity, and not upon the phase of the component in question. The author shows how to test this rule by his apparatus.

Four wave forms were built up of very different shape but all having the same harmonics from $I$ to 20. It was found that these four totally different wave forms were quite indistinguishable as to their sound impression. It is also stated that non-linear distortion occurs in tho ear. This is manifested by the fact that when a pure tone of sufficient intensity is heard, higher harmonics are formed in the ear; when two tones of different frequency are heard at the same time, new tones are formed with frequencies which are linear combinations of the two tones heard (combination tones). The most obvious combination tone is the difference tone and this is the one that was first discovered. 